\title{
Relationship between sleep deprivation and anxiety - experimental research perspective
}

\author{
Relação entre privação de sono e ansiedade na pesquisa básica
}

\author{
Gabriel Natan Pires ${ }^{1}$, Sergio Tufik ${ }^{1}$, Monica Levy Andersen ${ }^{1}$
}

\begin{abstract}
Sleep deprivation is a condition that is more and more observed in modern society bringing various neurobehavioral effects, being anxious states one of the main problems. Many studies have successfully demonstrated the relationship between sleep deprivation and anxiety in clinical research. As to basic experimentation, various models have been efficiently used in order to evaluate an anxious behavior. However, the same efficacy is not found on basic studies that deal with the relationship between paradoxical sleep and anxiety. The great majority of studies which approach this matter in animal models do not present results that may be applied to clinical practice and this is basically due to two reasons: inconsistency among results and lack of replicability as related to clinical studies. It has to be emphasized that the use of animal models is extremely useful, mainly under experimental conditions which cannot be ethically or plausibly be approached in human beings. So, the present theoretical assay tries to evaluate in a brief and critical manner the applicability of animal models in sleep deprivation under a translational perspective.
\end{abstract}

Keywords: Anxiety; Sleep; Basic research; Animal models; Translational medical research

\section{RESUMO}

A privação de sono é uma condição cada vez mais observada na sociedade moderna, resultando em diversos efeitos neurocomportamentais. Um dos principais efeitos comportamentais dessa condição é a proeminência de estados ansiosos. Diversos estudos têm demonstrado, com sucesso, a relação entre privação de sono e ansiedade na pesquisa clínica. Quanto à experimentação básica, diversos modelos têm sido eficientemente empregados na avaliação do comportamento do tipo ansioso. Todavia, a mesma eficácia não é encontrada nos estudos básicos, que abordam a relação entre privação de sono paradoxal e ansiedade. A maioria dos estudos que aborda essa relação em modelos animais não apresenta resultados passíveis de extrapolação à prática clínica, e isso se deve basicamente a dois motivos: inconsistência entre resultados e falta de replicabilidade em relação a estudos clínicos. Ressalta-se que 0 uso de modelo animais é extremamente útil, sobretudo em condições experimentais que não podem ser ética ou plausivelmente abordadas em seres humanos. Desse modo, o presente ensaio teórico busca avaliar, de modo sucinto e crítico, a aplicabilidade dos modelos animais de privação de sono, sob uma perspectiva translacional.

Descritores: Ansiedade; Sono; Pesquisa básica; Modelos animais; Pesquisa médica translacional

\section{INTRODUCTION}

Anxiety has been described as one of the most important consequences of sleep deprivation. This effect was first reported by Dement ${ }^{(1)}$, in the pioneer experiment with REM (rapid eye movement) sleep deprivation in human beings. In this study, in individuals deprived of REM sleep, the appearance of a triad of neurobehavioral comorbidities was noted, composed by increased anxiety associated with attention deficit and aggressiveness. Currently, several studies allow concluding that anxiety, especially in the form of generalized anxiety disorder, is an important consequence of sleep deprivation, both of total sleep or restricted to $\mathrm{REM}^{(2-4)}$. Inversely, anxiety disorders lead to significant alterations in the architecture and quality of sleep ${ }^{(5)}$. In this case, this relation becomes valid for all types of anxiety disorders, and is not limited to the generalized anxiety disorder.

The relevance of the correlation between anxiety and sleep deprivation may be verified by the large number of publications on these two themes. Many of these publications come from basic research, especially studies conducted in experimental animals. However, it is noted that animal experiments do not mimic the anxiogenesis observed in sleep deprived human beings ${ }^{(6)}$. In fact, many experiments performed in rodents indicate an anxiolytic condition due to lack of sleep.

${ }^{1}$ Universidade Federal de São Paulo - UNIFESP, São Paulo (SP), Brazil.

Corresponding author: Monica Levy Andersen - Rua Napoleão de Barros, 925 - Vila Clementino - Zip code: 04024-002 - São Paulo (SP), Brazil - Phone: (55 11) $2149-0155$ - E-mail: mandersen@unifesp.br/ ml.andersen12@gmail.com

Received on: Apr 16, 2012 - Accepted on: Aug 17, 2012 
The discrepancy in the relation between sleep deprivation and anxiety, when comparing the results of basic and clinical research, is not valued in literature. Nonetheless, the implication of this verification is worrisome, since it questions the translational applicability of basic studies in the area. In this way, the present theoretical study aims to evaluate, in a succinct and critical manner, the applicability of animal models of sleep deprivation from a translational perspective.

\section{Animal models of anxiety}

several animal models may be used to evaluate anxietylike behaviors in experimental animals. Indeed, these models are valuable experimental tools for the investigation of anxiety, and produce data of great relevance and clinical applicability. In general, these models are applied to small rodents (rats and mice), commonly used in biomedical experimentation. Analysis of the anxiety-like behavior in animals is based primarily on the quantification of latency, on the frequency and duration of specific behavioral parameters.

Among the most commonly used models for analysis of this behavior we point out the elevated plus maze, considered the gold standard for evaluation of anxiety in basic research ${ }^{(7,8)}$. This is a cross-shaped platform, elevated $50 \mathrm{~cm}$ from the floor, with two opposing arms open and two opposing arms closed laterally (Figure 1). By means of this equipment, the animal is place under a condition in which the natural tendency to explore the environment, an action that denotes anxiolysis,

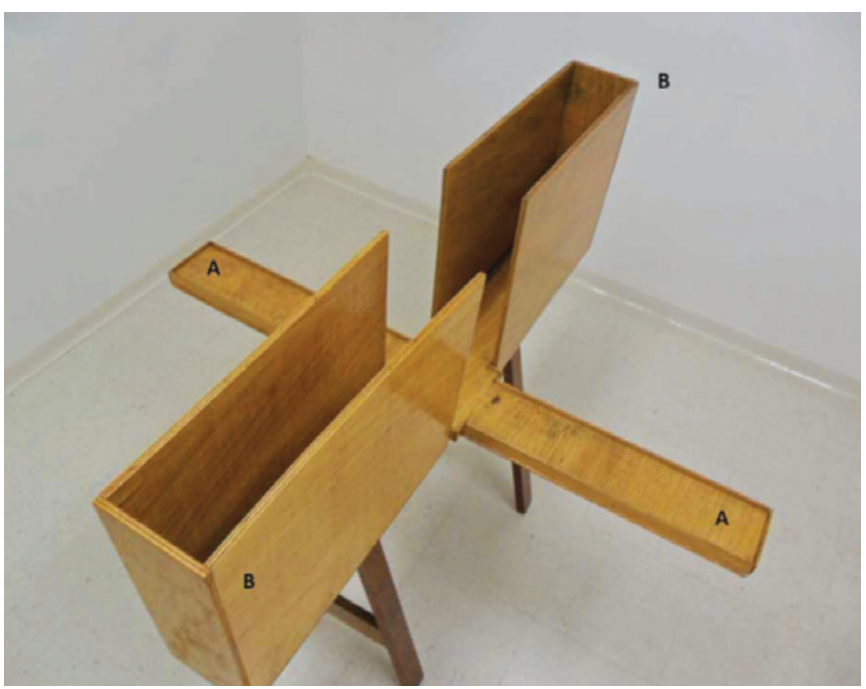

Figure 1. Elevated plus maze. This apparatus consists of a cross-shaped platform, elevated $50 \mathrm{~cm}$ from the floor, and with a pair of opposing open arms and a pair of opposing closed arms laterally. It is the gold standard method for evaluation of anxious-type behavior in rodents. (A) Open arms; (B) closed arms is confronted with the tendency to remain in a safe environment, represented by the closed arms of the platform, a condition that denotes anxiogenesis. Other similar models are capable of evaluating anxious-type behavior to different degrees, such as discriminative avoidance $\operatorname{task}^{(9)}$, the open field test ${ }^{(10)}$, the zero maze ${ }^{(11)}$, and the $\mathrm{T}$ maze ${ }^{(12)}$. Finally, the quantification of a few specific parameters may be indirectly related to anxiety. In this case, we highlight self-grooming, immobilization, locomotion, and the number of fecal boluses.

An alternative model to the classic methods of behavioral evaluation in experimental animals was recently proposed by Kalluef and Tuohima ${ }^{(13,14)}$. This model uses self-grooming as a parameter for inferring about anxiety-like behavior. It is observed that, despite classic measurements (latency, frequency, and duration), animals with low or high levels of anxiety are different in what regards to the microstructure and progression of this behavior. In animals with low levels of anxiety, self-grooming is performed in well-ordered and uninterrupted cephalocaudal progressions, denoting body cleaning but not anxiety. On the other hand, in animals with prominent anxious behavior, self-grooming is performed in fragmented and disorganized progressions. In this model, it is interesting to note how ethological observations, such as descriptions of the microstructure of the behavior of self-grooming in rodents, may be used in drawing up a research model with a high potential for translational application.

In spite of criticism and methodological drawbacks to most models of evaluation of anxiety-like behavior in rodents ${ }^{(15)}$, one can affirm that, in general, they are efficient, as long as correctly utilized. Even so, this is an area in constant renovation and under recurring theoretical reconsiderations, which result in adaptations to the models that already exist and the creation of new models. It is these adaptations that guarantee the applicability of these animal models to the most varied experimental conditions.

\section{Basic research in sleep deprivation and anxiety}

The applicability of animal models of anxiety described herein seems to not be repeated when sleep deprivation is introduced as an additional variable. In these cases, paradoxical sleep deprivation (analogous to the deprivation of REM sleep), seems to produce anxiolytic effects in most cases ${ }^{(16-19)}$. This effect is evident primarily by the increased time during which the sleep deprived animals remain in the open arm of the platform, when compared to animals not deprived of sleep. Nevertheless, 
there are reports of increased anxiety-like behavior under similar conditions ${ }^{(6,20)}$. Regarding total sleep deprivation, there are no studies conducted in basic research that have related it to anxiety-like behavior.

Despite the impossibility of affirming, with certainty, the reason for the discrepancy of data mentioned above, one can list, as possible causal factors, differences among species (rats versus mice), in the paradoxical sleep deprivation protocol and in handling and housing of the animals. Indeed, these are the main arguments presented by Silva et al. ${ }^{(6)}$ to justify the findings of increased anxiety in face of prior studies that demonstrated anxiolysis due to paradoxical sleep deprivation. Additionally, one should pay attention to the fact that the studies considered to demonstrate the inconsistency of data come from the use of the elevated plus maze. Therefore, one can indicate, as reasons for the disparity described, a possible lack of sensitivity, inaccuracy, or partial impropriety of the elevated plus maze when associated with paradoxical sleep deprivation.

\section{Consequences of disparities between basic and clinical research}

Regardless of the reasons for the discrepancies presented, the lack of consensus among the results presented herein hinders the translational applicability of the findings. Additionally, this verification is even stronger when considering that most of the animal studies do not mimic the condition of anxiogenesis found in sleep-deprived individuals. In fact, while a sleep-deprived individual presents a prominent state of anxiety, most of the animal studies show a decrease in anxiety-like behavior in analogous conditions. In this way, extrapolation of data from basic sciences to clinical practice is hampered. Studies that evaluate interventions in addition to the relation between sleep deprivation and anxiety become dubious. Since the correlation between sleep and anxiety in experimental science is not yet well established, the evaluation of additional variables is imprecise. For example, one could highlight studies that assess the effect of specific drugs on the anxiety-like behavior in animals that are sleep deprived or under similar circumstances. Since there is no consensus as to the direct relation between the primary variables, the evaluation of the pharmacological effect becomes inaccurate. This is the case, for example, of Huang et al. ${ }^{(21)}$, who evaluated the effect of drugs, such as eszopiclone and zolpidem on sleep and anxious behavior, and of Garg and Kumar ${ }^{(22)}$, who investigated the effect of trazodone and imipramine in the relation between these two variables.

Based on the above-mentioned arguments, we observe that under current conditions, the relevance of basic studies that cover the interface between sleep and anxiety is compromised. Thus, the discussion of methodological alternatives that intend to solve this problem becomes necessary.

\section{Methodological alternatives}

As was highlighted before, the relevance of the use of animal models in research on anxiety disorders is unquestionable. Nevertheless, this same relevance is not found in studies that involve sleep deprivation, due to inconsistency of the results coming from animal research and to the lack of reproducibility of clinical data in basic science. In this sense, it is necessary to discuss alternatives to the basic models currently used in approaching the association between sleep deprivation and anxiety, so that these may be equally applicable. Some alternatives to this panorama are discussed below.

Currently, the reasons for the aforementioned discrepancies are not known. Even considering that there are studies that show an increase in anxiety-like behavior by sleep deprivation, especially over the last decade, the volume of publications with these characteristics does not yet allow these results to be unanimously extrapolated. For this, the replication of these data is necessary, in order to reaffirm their translational applicability. It is expected that with the replication of the findings, a consensus will be reached regarding anxiolysis or anxiogenesis as a behavioral result of paradoxical sleep deprivation in animals. Consequently, this fact would make the previous opposing facts as resulting from occasional variations. Additionally, a possible verification of the replication of these experiments would be the maintenance of the inconsistencies of the results. In this hypothetical case, the inapplicability of animal models of anxious behavior for experimental situations that involve paradoxical sleep would be demonstrated.

It is appropriate to investigate properly the reasons for the cited discrepancies. This would allow refining of behavioral techniques used in basic research, thus guaranteeing greater applicability of the data obtained. Even if the reason for the said discrepancies is not known, one way to guarantee data reproducibility is to repeat exclusively to protocols of the experiments in which anxiogenesis was obtained as an effect of sleep deprivation. This measure would assure the applicability 
of results of future studies, based on protocols that effectively mimic the association found in human beings.

Finally, other behavioral methods may be sought for assessing the anxiety-like behavior, besides the elevated plus maze. In fact, Garg and Kumar ${ }^{(22)}$ used, in an interesting way, several alternative tests such as the actophotometer and the zero maze, besides the elevated plus maze. However, the specific context addressed by the authors, added to the lack of similar studies, precludes the evaluation of consistency and the applicability of these tests. We further point out the potential use of the grooming evaluation algorithm, described earlier. This protocol has been used with success to evaluate anxiety-like behavior in various contexts $^{(23-26)}$, although there are still no results described in literature with the use of this method as to sleep deprivation.

\section{CONCLUSIONS}

Sleep deprivation is a condition increasingly more observed in modern society, which results in various neurobehavioral effects. This fact is sufficiently strong to guarantee the importance of research on the interface between sleep deprivation and anxiety. Indeed, clinical studies brought to light evidence and have detailed this relationship in an interesting way. Nevertheless, we demonstrated that basic studies on the association between sleep deprivation and anxiety do not replicate it efficiently.

From a translational perspective, the use of animal models is valid since it enables the application of experimental conditions that could not be plausibly or ethically used in human beings. However, the inconsistency of data obtained in animal research, added to the disparity, when compared to the results of clinical research, impairs the use of a translational approach. Knowing the potential importance of animal models for the investigation of the relation between sleep deprivation and anxiety, we propose that the basic studies in this area should be replicated. This recommendation is especially valid for those protocols that point to anxiogenesis as a result of sleep deprivation, similar to the primary observations made in human beings. Additionally, we strongly suggest the use of new and alternative methodologies for the evaluation of the association between the studied themes, seeking protocols sufficiently sensitive and applicable to these experimental conditions. We hope that these recommendations enable the extrapolation, in the future, of data on sleep and anxiety obtained in animal research to clinical practice.

\section{ACKNOWLEDGMENTS}

Financial support: AFIP, CNPq and FAPESP-CEPID [FAPESP/CEPID \#98/14303-3].

\section{REFERENCES}

1. Dement W. The effect of dream deprivation. Science. 1960;131(3415):1705-7.

2. Labbate LA, Johnson MR, Lydiard RB, Brawman-Mintzer 0, Emmanuel N, Crawford M, et al. Sleep Deprivation in social phobia and generalized anxiety disorder. Biol Psychiatry. 1998;43(11):840-2.

3. Sagaspe P, Sanchez-Ortuno M, Charles A, Taillard J, Valtat C, Bioulac B, et al. Effects of sleep deprivation on Color-Word, Emotional, and Specific Stroop interference and on self-reported anxiety. Brain Cogn. 2006;60(1):76-87.

4. Roy-Byrne PP, Uhde TW, Post RM. Effects of one night's sleep deprivation on mood and behavior in panic disorder. Patients with panic disorder compared with depressed patients and normal controls. Arch Gen Psychiatry. 1986; 43(9):895-9.

5. Andersen M, Pires G, Tufik S. Sono em condições psiquiátricas. In: Kapczinski F, Quevedo J, Izquierdo I, editores. Bases biológicas dos transtornos psiquiátricos. Porto Alegre: Mcgraw Hill; 2011. p. 289-310

6. Silva RH, Kameda SR, Carvalho RC, Takatsu-Coleman AL, Niigaki ST, Abílio VC, et al. Anxiogenic effect of sleep deprivation in the elevated plus-maze test in mice. Psychopharmacology (Berl). 2004;176(2):115-22.

7. Komada M, Takao K, Miyakawa T. Elevated plus maze for mice. J Vis Exp [Internet]. 2008 [cited 2012 Set 17]; (22): [about 3p]. Available from: http:// www.ncbi.nlm.nih.gov/pmc/articles/PMC2762911/pdf/jove-22-1088.pdf

8. Carobrez AP, Bertoglio LJ. Ethological and temporal analyses of anxiety-like behavior: the elevated plus-maze model 20 years on. Neurosci Biobehav Rev. 2005;29(8):1193-205.

9. Silva RH, Frussa-Filho R. The plus-maze discriminative avoidance task: a new model to study memory-anxiety interactions. Effects of chlordiazepoxide and caffeine. J Neurosci Methods. 2000;102(2):117-25.

10. Prut $L$, Belzung $C$. The open field as a paradigm to measure the effects of drugs on anxiety-like behaviors: a review. Eur J Pharmacol. 2003;463(1-3):3-33.

11. Shepherd JK, Grewal SS, Fletcher A, Bill DJ, Dourish CT. Behavioural and pharmacological characterisation of the elevated "zero-maze" as an animal model of anxiety. Psychopharmacology (Berl). 1994;116(1):56-64.

12. Graeff FG, Netto CF, Zangrossi H Jr. The elevated T-maze as an experimenta model of anxiety. Neurosci Biobehav Rev. 1998;23(2):237-46.

13. Kalueff AV, Tuohimaa P. Grooming analysis algorithm for neurobehavioural stress research. Brain Res Brain Res Protoc. 2004;13(3):151-8.

14. Kalueff $A V$, Tuohimaa $P$. The grooming analysis algorithm discriminates between different levels of anxiety in rats: potential utility for neurobehavioural stress research. J Neurosci Methods. 2005;143(2):169-77.

15. Kalueff AV, Wheaton M, Murphy DL. What's wrong with my mouse model? Advances and strategies in animal modeling of anxiety and depression. Behav Brain Res. 2007;179(1):1-18

16. Alvarenga $T A$, Patti $C L$, Andersen ML, Silva RH, Calzavara MB, Lopez GB, et al. Paradoxical sleep deprivation impairs acquisition, consolidation, and retrieval of a discriminative avoidance task in rats. Neurobiol Learn Mem. 2008;90(4):624-32.

17. Suchecki D, Tiba PA, Tufik S. Hormonal and behavioural responses of paradoxical sleep-deprived rats to the elevated plus maze. J Neuroendocrinol. 2002;14(7):549-54

18. Pokk P, Zharkovsky A. The effects of drugs acting at GABA-benzodiazepinebarbiturate receptor complex on the behaviour of sleep-deprived mice. Pharmacol Toxicol. 1995;76(1):23-8.

19. Pokk P, Zharkovsky A. The effects of flumazenil, Ro 15-4513 and beta-CCM on the behaviour of control and stressed mice in the plus-maze test. J Physio Pharmacol. 1997;48(2):253-61.

20. Vollert C, Zagaar M, Hovatta I, Taneja M, Vu A, Dao A, et al. Exercise prevents sleep deprivation-associated anxiety-like behavior in rats: potential role of oxidative stress mechanisms. Behav Brain Res. 2011;224(2):233-40. 
21. Huang MP, Radadia K, Macone BW, Auerbach SH, Datta S. Effects of eszopiclone and zolpidem on sleep-wake behavior, anxiety-like behavior and contextual memory in rats. Behav Brain Res. 2010;210(1):54-66.

22. Garg R, Kumar A. Possible role of citalopram and desipramine against sleep deprivation-induced anxiety like-behavior alterations and oxidative damage in mice. Indian J Exp Biol. 2008;46(11):770-6.

23. Enginar N, Hatipoğlu I, Firtina M. Evaluation of the acute effects of amitriptyline and fluoxetine on anxiety using grooming analysis algorithm in rats. Pharmacol Biochem Behav. 2008;89(3):450-5
24. Denmark A, Tien D, Wong K, Chung A, Cachat J, Goodspeed J, et al. The effects of chronic social defeat stress on mouse self-grooming behavior and its patterning. Behav Brain Res. 2010;208(2):553-9.

25. Hart PC, Bergner CL, Smolinsky AN, Dufour BD, Egan RJ, Laporte JL, et al. Experimental models of anxiety for drug discovery and brain research. Methods Mol Biol. 2010;602:299-321.

26. Kalueff AV, Tuohimaa P. Mouse grooming microstructure is a reliable anxiety marker bidirectionally sensitive to GABAergic drugs. Eur J Pharmacol. 2005; 508(1-3):147-53. 